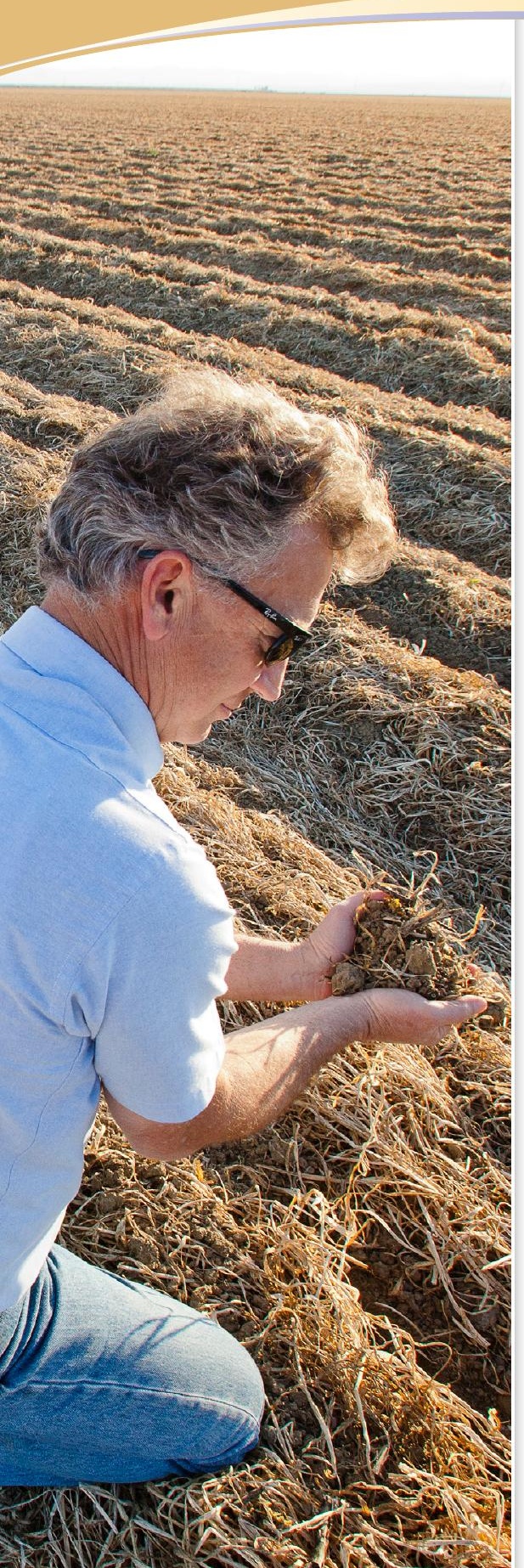

\title{
CONSEJOS SOBRE LA SEQUÍA \\ Recuperar los suelos salinos, sódicos y salino-sódicos
}

os suelos con un alto contenido de sal causan que las plantas tengan un crecimiento pobre, interfieren en la producción agrícola y reducen el uso eficiente del agua. Algunos suelos salinos tienen problemas físicos que reducen la infiltración del agua y aumentan el escurrimiento en la superficie. La recuperación de los suelos salinos puede llevar a un mejor manejo y uso eficiente del agua y producción agrícola.

El primer paso para recuperar los suelos salinos es diagnosticar el problema. Existen tres tipos de suelos afectados por la sal: salinos, sódicos y salino-sódicos. Cada uno de estos tres tipos de suelos salinos tiene un impacto diferente en el crecimiento de las plantas y requiere de diferentes estrategias de recuperación, por lo tanto se debe determinar el tipo de suelo afectado por la sal antes de cultivación o recuperación. La información en la tabla 1 se usa para clasificar los suelos salinos. Típicamente, entre los métodos usados para determinar el tipo de suelo salino se encuentran la conductividad eléctrica (o EC, por sus siglas en inglés) (una medida del total de sales solubles) y el porcentaje intercambiable de sodio (o ESP, por sus siglas en inglés) (el índice de sitios de intercambio de cationes ocupados por el sodio) o EC y el índice de absorción de sodio (o SAR, por sus siglas en inglés) (la proporción de sodio en relación al calcio y magnesio solubles). Otros buenos indicadores pueden ser la condición física/estructura del suelo y el pH.

\section{Suelos salinos}

Los suelos salinos tienen un alto contenido de sales solubles, como lo indica un EC $>4 \mathrm{dS} \mathrm{m}^{-1}$ (tabla 1). Los suelos salinos con frecuencia exhiben depósitos o costras blancas de sal, visibles sobre la superficie de la tierra. Típicamente los suelos salinos no muestran una estructura pobre, y como resultado, tienen índices adecuados de infiltración de agua.
ANTHONY O'GEEN,

especialista en

recursos del suelo

de Extensión

Cooperativa,

Universidad de

California, Davis 


\section{Suelos sódicos}

Los suelos sódicos tienen una alta cantidad de sodio intercambiable en los sitios de intercambio de cationes. Estos suelos se caracterizan por tener un ESP > 15\% (tabla 1). Un índice alto de absorción de sodio $(\mathrm{SAR}>13)$ puede usarse como indicador para el ESP. Los suelos sódicos tienen una baja salinidad $\left(\mathrm{EC}<4 \mathrm{dS} \mathrm{m}^{-1}\right)$ y con frecuencia un alto $\mathrm{pH}(>8.5)$. Tienen por lo general un color oscuro y se les llama con frecuencia suelos "álcali negro". El agua de riego baja en salinidad puede incrementar la dispersión (o sellado) de la tierra y reducir la infiltración de suelos sódicos.

Los suelos sódicos exhiben una condición física pobre porque el sodio intercambiable dispersa minerales de arcilla, causando la degradación de la estructura del suelo. Los minerales de arcilla dispersos se mueven con el agua filtrada y eventualmente tapan poros grandes de la tierra que son críticos en la aireación y movimiento del agua. Esto, a su vez, reduce el índice de infiltración y permeabilidad del suelo. Estas capas impenetrables se encuentran con frecuencia en o cerca de la superficie de la tierra.

\section{Suelos salino-sódicos}

Existen también suelos sódicos con un pH más bajo y sin la coloración oscura. Muchos de los suelos del lado oeste del Valle de San Joaquín, con frecuencia dominados por las sales de sulfato de sodio,

Table 1. Propiedades usadas para clasificar un suelo afectado por la sal

\begin{tabular}{|l|c|c|c|c|c|}
\hline $\begin{array}{l}\text { Tipo del suelo salino/ } \\
\text { sódico }\end{array}$ & $\begin{array}{c}\text { Conductividad } \\
\text { eléctrica } \\
\text { (EC) }\end{array}$ & $\begin{array}{c}\text { Sodio } \\
\text { intercambiable } \\
\text { (ESP) }\end{array}$ & $\begin{array}{c}\text { Índice de } \\
\text { absorción de } \\
\text { sodio (SAR)* }\end{array}$ & pH & $\begin{array}{c}\text { Condición } \\
\text { física }\end{array}$ \\
\hline suelo agrícola típico & $<4$ & $\%$ & & & \\
\hline suelo salino & $<4$ & $<15$ & $<13$ & $<8.0$ & buena \\
\hline suelo sódico solamente & $<4$ & $>15$ & $<13$ & $<8.5$ & buena \\
\hline suelo salino-sódico & $>4$ & $>15$ & $>13$ & $>8.5$ & pobre \\
\hline
\end{tabular}

*SAR del extracto de agua del suelo son tanto sódicos como salinos. Los suelos salino-sódicos tienen un ESP alto (> 15\%) y una salinidad alta $\left(\mathrm{EC}>4 \mathrm{dS} \mathrm{m}^{-1}\right)($ tabla 1$)$. Típicamente, estos suelos tienen una mejor condición física que los suelos no salino-sódicos, porque su alto contenido de sal soluble mantiene floculados a los minerales arcillosos (sin dispersarse) y estable la estructura edáfica o del suelo. De manera similar, el contenido de sal amortigua el $\mathrm{pH}$ a 8.5 o menos. Los procesos de recuperación deben abordar tanto la salinidad como el intercambio de sodio en los suelos salino-sódicos. El agua de riego de baja salinidad puede reducir la infiltración de los suelos salino-sódicos.

Los suelos afectados por la sal pueden causar una variedad de problemas. El alto contenido de sal causa un estrés osmótico que hace que las células de las plantas concentren solutos, permitiendo que el agua se desplace a las raíces. Esto absorbe la energía de la planta y tiene el potencial de reducir el crecimiento. El alto nivel de salinidad en la zona de las raíces puede reducir drásticamente la producción del cultivo. Mientras que los suelos salinos tienen una cantidad límite de EC $>4 \mathrm{dS} \mathrm{m}^{-1}$, los cultivos que son tolerantes a la sal pueden crecer en suelos con una mayor salinidad, pero algunos cultivos son sensibles a valores de EC por debajo de esta cantidad límite. Para una lista de los promedios de tolerancia a la sal de algunos cultivos, vea Hanson (2006) y otras publicaciones que son parte de las referencias al final de esta publicación. Un alto nivel de salinidad es usualmente el resultado combinado de la carga de sal del material parental del suelo y un desagüe pobre. Las sales se acumulan con el tiempo si el agua no puede ser filtrada fuera del perfil del suelo. De igual manera, los suelos salinos se pueden formar donde ocurre un nivel freático alto junto con agua de riego que tiene un alto contenido de sales, e incluso donde el agua de riego contiene niveles moderados a altos de sal.

El exceso de sodio en los suelos sódicos es tóxico para algunos cultivos, particularmente para árboles que son expuestos a este elemento durante varios años. El sodio también compite con otros cationes como el potasio, calcio y magnesio en ser absorbidos por la planta, y eso puede llevar a una deficiencia de nutrientes en 
esta (Davis et al. 2014). El alto pH que es algo característico de los suelos sódicos reduce la disponibilidad de los nutrientes más esenciales de las plantas.

\section{Recuperación de los suelos salinos}

La estrategia de recuperación de suelos salinos más común es drenar las sales de las zona de las raíces con agua de buena calidad. Entre los diversos métodos se incluyen el riego por anegación continuo o intermitente y por aspersión. La cantidad de agua necesaria para reducir la salinidad del suelo a un nivel específico puede ser determinado en base a las curvas de recuperación o con la ecuación 1 (Hanson et al. 2006):

$$
D_{w}=\left(k \times D_{s} \times E C_{e i}\right) \div E C_{\text {ef }}
$$

donde:

$$
\begin{aligned}
& D_{w}=\text { profundidad del agua infiltrada (en pies) } \\
& \begin{aligned}
& D_{s}= \text { profundidad del suelo que va a ser recuperado (en pies) } \\
& k= 0.45 \text { para suelos orgánicos, } 0.30 \text { para suelos de textura fina } \\
& \text { y } 0.10 \text { para suelos de textura áspera } \\
& E C_{e i}=\text { salinidad inicial del suelo } \\
& E C_{e f}=\text { salinidad del suelo final deseada }
\end{aligned}
\end{aligned}
$$

\section{Riego de anegación continuo}

El riego de anegación continuo incluye la aplicación de grandes volúmenes de agua que permanece estancada hasta que se ha removida suficiente sal de la zona de las raíces. La cantidad de agua necesaria puede determinarse usando la ecuación 1 .

La salinidad final deseada depende de la tolerancia del cultivo a la salinidad. La cantidad real de agua requerida depende del tipo de suelo y del EC inicial. Por lo tanto, es necesario monitorear la salinidad del suelo durante el periodo de recuperación y después para determinar si se necesitan hacer ajustes adicionales.

\section{Recuperación mediante riego de anegación intermitente} o de aspersión

Los métodos de recuperación por medio del riego por anegación intermitente o de aspersión pueden ser usados para ahorrar agua mientras se recupera el suelo. En lugar de usar el riego de anegación como una forma de aplicación continua, se pueden aplicar varias cantidades pequeñas de agua como riego de anegación o aspersión, seguido por periodos de secado. Los ciclos de riego y secado filtran de manera efectiva las sales de los poros más pequeños de la tierra usando menos agua (de una a dos terceras partes) que con el riego de anegación continuo. Para calcular la cantidad de agua necesaria, puede usar la ecuación 1 , substituyendo $\mathrm{k}=0.10$ para todos los tipos de suelos (Hanson et al. 2006).

Una de las desventajas de la aplicación del riego de anegación intermitente y de aspersión es el periodo relativamente largo que se requiere para completar los ciclos múltiples de riego y desagüe/ secado, comparado con el riego de anegación continuo, que se lleva a cabo de una sola vez. Además, en áreas con una evaporación alta, los métodos de recuperación intermitente pueden ser problemáticos porque las sales filtradas solo a una profundidad superficial debido a las pequeñas aplicaciones iniciales de agua pueden regresar a la superficie del suelo durante el periodo de secado después de la aplicación de agua. Por esta razón, la filtración es mucho más efectiva cuando se lleva a cabo durante el invierno, cuando la evaporación se da a un nivel mínimo.

\section{Desagüe}

Se requiere de un desagüe adecuado para poder recuperar los suelos salinos. Los suelos con un nivel freático superficial requieren de un sistema de desagüe subsuperficial para que el agua drenada pueda salir del campo de cultivo. De otra manera, el riego de anegación continuo puede llegar a saturar el suelo hasta la superficie. Con el uso de baldosas de desagüe apropiadamente espaciadas en el campo de cultivo, el nivel freático se reduce en general, aunque se mantiene lo más bajo justo por encima de la baldosa. Si el nivel freático se mantiene muy elevado entre las líneas de desagüe, se 
debe a que el espacio entre las líneas de desagüe es muy grande y podría requerirse de la instalación de una línea adicional entre las líneas existentes. El riego de anegación intermitente o de aspersión también mejora la filtración en áreas que se encuentran distantes del desagüe. El riego de aspersión es por lo general el método de recuperación preferido bajo estas condiciones.

\section{Recuperación de suelos sódicos y salino-sódicos}

Los suelos sódicos y salino-sódicos son recuperados reemplazando el sodio intercambiable por calcio. Esto se logra comúnmente agregando gypsum (yeso), pues es relativamente soluble y barato. Sin embargo, si los suelos son naturalmente altos en carbonato de calcio (cal), se les puede aplicar sulfuro elemental de grano fino o ácido sulfúrico sin tener que aplicar calcio directamente a la tierra. El sulfuro, junto con la ayuda de los microbios de la tierra, se oxida en la tierra húmeda para formar ácido sulfúrico, el cual disuelve a la cal, provocando que su calcio esté disponible en solución para reemplazar el sodio en los sitios de intercambio de tierra. Este es un proceso bastante lento y dependiente del área de la superficie de las partículas de sulfuro que son expuestas. El sulfuro debe mezclarse en la capa superficial del suelo. El ácido puede ser aplicado al suelo o inyectarse al agua de riego. Debe ser cuidadoso en asegurarse que el calcio alcance todas las profundidades que han sido designadas para una recuperación. Los suelos salino-sódicos deben ser filtrados con agua de buena calidad (baja en sodio) después de ser tratados con acondicionadores portadores de calcio o sulfuro. Así como con la recuperación de suelos salinos, se debe mantener un desagüe adecuado tanto para suelos sódicos como salino-sódicos para expulsar el sodio fuera del sistema (Horneck et al. 2007).

La restauración de suelos sódicos y salino-sódicos es un proceso lento. La recuperación ocurre secuencialmente con la profundidad conforme el calcio satura los sitios donde se da el intercambio de cationes y se desliza por el perfil del suelo. Por lo tanto, si se desea una recuperación más profunda, se necesita agregar suficiente yeso para asegurar que la recuperación se extiende a toda la profundidad deseada. Sin embargo, lo mejor es no aplicar todo el yeso de una sola vez. Es mejor y más efectivo agregarlo en incrementos anuales hasta alcanzar el porcentaje de sodio intercambiable (ESP) a la profundidad deseada. Materiales orgánicos como las compostas y estiércol, así como el uso de cultivos de cubierta tolerantes a la sal, pueden ser útiles en mantener la estructura del suelo superficial para lograr una infiltración adecuada y el término del proceso de recuperación (Davis et al. 2014). También se recomienda el monitoreo de los niveles de salinidad y sodicidad.

\section{¿Cuánto material se debe aplicar para recuperar un suelo salino-sódico y sódico?}

\section{Yeso (Gypsum)}

La cantidad de yeso que se necesita para recuperar un suelo depende del ESP inicial, el nivel final de sodio intercambiable que se desea, la capacidad del suelo para absorber sodio o calcio, la densidad a granel del suelo y la profundidad total del suelo que va a ser recuperado. La cantidad de yeso que se necesita-llamada requerimiento de yesose determina mediante un análisis de laboratorio. En ausencia de este tipo de análisis, los rangos recomendados son de 3 a 5 toneladas por acre. La regla general para calcular la cantidad de agua que se debe aplicar es la de que alrededor de 3 pulgadas de agua por acre disuelven de 1 a 2 toneladas de yeso.

Ejemplo 1. Cálculo para el requerimiento de yeso:

Su suelo contiene un CEC de 20 miliequivalentes (meq) por cada 100 gramos de tierra y un ESP de $20 \%$ y usted desea un ESP final de aproximadamente un 5\%. En este cálculo es aceptable asumir que el SAR es casi equivalente al ESP.

Calcule el porcentaje de sodio intercambiable que debe reemplazar con calcio:

$$
20 \% \text { (ESP medido) }-5 \% \text { (ESP deseado) }=\text { ESP de } 15 \%,
$$

lo que significa que un $15 \%$ del sodio intercambiable debe ser reemplazado con calcio $(\mathrm{Ca})$ para obtener el ESP deseado. 
Ahora convierta el porcentaje de sodio intercambiable que desea reemplazar en miliequivalentes de sodio que va a ser reemplazado:

$0.15(15 \%) \times 20$ meq de CEC/100g de tierra $=3 \mathrm{meq} / 100 \mathrm{~g}$ de tierra

Como regla general, se requieren 1.7 toneladas de yeso $(100 \%$ pureza equivalente) por miliequivalente de sodio por $100 \mathrm{~g}$ de tierra por acre-pie de tierra:

$3 \mathrm{meq} / 100 \mathrm{~g}$ de tierra $\times 1.7=5.1$ toneladas de yeso que se necesitan para recuperar 1 acre de tierra con una profundidad de 0 a 1 pie.

Por lo tanto, se requieren 5 toneladas de yeso puro por acre para reutilizar las primeras 12 pulgadas de suelo. Podría también ser mejor si se incorpora la mitad de esta cantidad en el suelo durante el otoño el primer año y la segunda mitad en el siguiente otoño. Si se desea recuperar el suelo a una mayor profundidad, usted puede continuar agregando yeso en cantidades similares anualmente, asegurándose de obtener muestras de tierra para monitorear el proceso de recuperación conforme llega a la profundidad deseada. Asegúrese de ajustar este cálculo para el grado específico de yeso que está usando y la profundidad deseada.

\section{Sulfuro}

El sulfuro se usa algunas veces para recuperar suelos sódicos que contienen cal. En este caso, se requiere realizar pruebas del suelo para determinar la cantidad de cal presente. El proceso de recuperación consume mucho tiempo ya que el sulfuro debe ser oxidado primero por la bacteria de la tierra (Thiobacillus) para formar ácido sulfúrico. Esto, a la vez, disuelve la cal. Sin embargo, el proceso de oxidación requiere de tierra caliente, bien ventilada y húmeda, y se limita al área superficial de las partículas de la tierra. Puede ser que el sulfuro que se aplica en el otoño tenga poco efecto hasta el siguiente verano.

\section{Ácido sulfúrico}

El ácido sulfúrico, cuando se mezcla directamente con la tierra o se agrega al agua de riego, disuelve la cal que se encuentra presente en la tierra. Por lo tanto, libera el calcio libre que puede intercambiarse por sodio en la tierra. El proceso es relativamente rápido, pero el ácido sulfúrico es difícil y peligroso de manejar.

Otros acondicionadores de tierra

El cloruro de calcio, nitrato de calcio, cal de azufre y sulfato férrico son otros acondicionadores de tierra que pueden usarse en la recuperación de suelos sódicos. El cloruro de calcio y el nitrato de calcio son materiales altamente solubles, pero son costosos.

El requerimiento de yeso puede ser calculado como se explica arriba, y con frecuencia se incluye como parte de un análisis de laboratorio agrícola. No obstante, debe recordar que el yeso que está comercialmente disponible no es $100 \%$ puro y debe aplicarlo usando una mayor tasa de aplicación para compensar por la falta de pureza. Las tasas de aplicación para otros acondicionadores pueden ser calculadas en base a la equivalencia del acondicionador por tonelada de yeso puro. Para calcular la cantidad de yeso impuro o de otros acondicionadores, use la tabla 2 y la ecuación 2 :

Toneladas aplicadas requeridas $=100 \div \%$ de pureza $\times$ equivalente en toneladas

Tabla 2. Tonelaje equivalente a 1 tonelada de yeso puro para varios acondicionadores

\begin{tabular}{|l|c|}
\hline Acondicionador & $\begin{array}{c}\text { Aplicación equivalente } \mathbf{1} \text { tonelada } \\
\text { de yeso puro }\end{array}$ \\
\hline yeso & \begin{tabular}{c} 
Toneladas $(\mathbf{t})$ \\
\hline $\mathrm{t}$ aplicada $=1 \mathrm{t}$ de yeso
\end{tabular} \\
\hline sulfuro & $0.19 \mathrm{t}$ aplicada $=1 \mathrm{t}$ de yeso \\
\hline ácido sulfúrico & $0.61 \mathrm{t}$ aplicada $=1 \mathrm{t}$ de yeso \\
\hline sulfato férrico & $1.09 \mathrm{t}$ aplicada $=1 \mathrm{t}$ de yeso \\
\hline cloruro de calcio & $0.86 \mathrm{t}$ aplicada $=1 \mathrm{t}$ de yeso \\
\hline nitrato de calcio & $1.06 \mathrm{t}$ aplicada $=1 \mathrm{t}$ de yeso \\
\hline sulfuro de cal & $0.78 \mathrm{t}$ aplicada $=1 \mathrm{t}$ de yeso \\
\hline
\end{tabular}


Ejemplo 2. ¿Cuánto yeso (al 60\% de pureza) debe aplicarse si el requerimiento de yeso es de 3 toneladas por acre?

Equivalente en toneladas $=1.00$ (de la tabla 2)

Cantidad aplicada $=100 / 60 \times 1=1.67$ toneladas

Si el requisito de yeso es de 3 toneladas por acre, entonces $3 \times 1.67=5$ toneladas por acre de yeso de un $60 \%$ de pureza es la cantidad que debe aplicarse.

Ejemplo 3. ¿Qué cantidad de ácido sulfúrico (80\% de pureza) debe aplicarse si el requisito de yeso es de 4 toneladas por acre?

Equivalente en toneladas $=0.61$ (de la tabla 2)

Cantidad aplicada $=100 / 80 \times 0.61=0.76$ tonelada

Por cada tonelada de yeso requerido, se debe aplicar 0.76 tonelada de ácido sulfúrico al $80 \%$ de pureza. La cantidad total a aplicarse es de $4 \times 0.76=3$ toneladas por acre de ácido sulfúrico.

\section{Referencias}

Davis, J. G., R. M.Waskom, and T. A. Bauder. 2014. Managing sodic soils. Colorado State University Extension Publication no. 0.504. www.ext.colostate.edu/pubs/crops/00504.html.

Grattan, S. 2002. Irrigation water salinity and crop production. UC ANR Publication 8066. http://anrcatalog.ucdavis.edu.

Hanson, B. R., S. R. Grattan, and A. Fulton. 2006. Agricultural salinity and drainage. UC ANR Publication 3375. http:// anrcatalog.ucdavis.edu.

Horneck, D. A., J. W. Ellsworth, B. G. Hopkins, D. M. Sullivan, and R.G. Stevens. 2007. Managing salt-affected soils for crop production. A Pacific Northwest Extension Publication:

Oregon State University, University of Idaho, and Washington State University PNW 601-E. 
Esta publicación fue escrita y producida por la División de Agricultura y Recursos Naturales (ANR, por sus siglas en inglés) de la Universidad de California bajo un acuerdo con el Departamento de Recursos del Agua de California (Department of Water Resources).

Para más información sobre las publicaciones y otros productos de ANR, visite el catálogo en línea de ANR Communication Services en anrcatalog.ucanr.edu/ o llame al 1-800-9948849. También puede pedirlas por correo electrónico o solicitar un catálogo impreso de nuestros productos escribiendo a

University of California

Agriculture and Natural Resources

Communication Services

2801 Second Street

Davis, CA 95618

Telephone: 1-800-994-8849

E-mail: anrcatalog@ucanr.edu

(C2018 The Regents of the University of California. Este trabajo se publica bajo la Licencia Internacional Creative Commons Attribution-NonCommercial-NoDerivatives 4.0. Para una copia de esta licencia, visite http://creativecommons.org/licenses/by-nc-nd/4.0/ o envie una carta a Creative Commons, PO Box 1866, Mountain View, CA 94042, USA

Publicación 8629

ISBN-13: 978-1-62711-011-2

Esta publicación es una traducción de Drought Tip: Reclaiming Saline, Sodic, and SalineSodic Soils, ANR Publication 8519, publicada en 2015. Traducción por Leticia Garcia-Irigoyen.

La Universidad de California prohíbe la discriminación o el hostigamiento, contra cualquier empleado o persona que busque empleo en la Universidad de California, por razones de raza, color, origen nacional, religión, sexo, identidad en función del género, embarazo (inclusive embarazo, parto y condiciones médicas relacionadas con el embarazo o el parto), incapacidad física o mental, estado de salud (casos de cáncer o de características genéticas), información genética (inclusive historial médico familiar), ascendencia, estado civil, edad, preferencia sexual, ciudadanía o por haber prestado servicio militar (según lo define la Ley de Derechos a Contratación y Recontratación de los Servicios Uniformados de 1994: servicio en el servicio militar incluye: membresía, solicitud de membresía, desempeño de servicio, solicitud de servicio u obligación de servicio en los servicios uniformados) o en cualquiera de sus programas o actividades.

La política de la Universidad también prohíbe represalias contra cualquier empleado o persona que busque empleo o cualquier persona que participe en sus programas y actividades y que haya presentado una queja por discriminación o acoso sexual según estas reglas. La política de la Universidad se propone concordar con las disposiciones de las leyes federales y estatales procedentes.

Las preguntas sobre la política antidiscriminatoria de la Universidad pueden dirigirse a: John Sims, Affirmative Action Contact y Title IX Officer, University of California Division of Agriculture and Natural Resources, 2801 Second Street, Davis, CA, 95618 (530-750-1397).

Email: jsims@ucanr.edu. Website: http://ucanr.edu/sites/anrstaff/Diversity/Affirmative_ Action/.

Se puede encontrar una copia electrónica de esta publicación en el catálogo del sitio web de ANR Communication Services, anrcatalog.ucanr.edu/.

UC. La exactitud técnica de esta publicación fue evaluada anónimamente por científicos y otros profesionales calificados de la Universidad de California. Este proceso de evaluación fue supervisado por Allan Fulton, editor asociado de ANR para Ciencias del Suelo, Aire y Agua.

web-3/18-LR/BG 